\title{
HISTOPATHOLOGY OF THE TELENCEPHALON AND DIENCEPHALON OF TILAPIA NILOTICA EXPOSED TO SUBLETHAL DOSE OF MALATHION S-[1,2-DI-(ETHOXYCARBONYL ETHYL) DIMETHYL PHOSPHOROTHIOLOTHIONATE]
}

\author{
EDNA A. AMPARADO \\ Institute of Biology, University of the Philippines, Diliman, Quezon City, Philippines
}

\begin{abstract}
A 35-day exposure of Tilapia nilotica embryos to sublethal doses of $3.0 \mathrm{ppm}$ and $0.3 \mathrm{ppm}$ malathion, S-[1,2-di-(ethoxycarbonyl ethyl) dimethyl phosphorothiolothionate], commercial grade, EC 57, produces cellular and ultrastructure changes in the brain. A number of nuclear centers of the treated animals are markedly larger than those of the control. Aberrant features observed in day- 45 embryos are the neoplastic masses and increased vascularization. Ultrastructure defects include the presence of nuclear blebs, cytoplasmic vacuolations and increased lysosomal bodies.
\end{abstract}

\section{INTRODUCTION}

The reliance of agriculture on pesticides to increase crop yield has resulted in the extensive and intensive use of these chemicals. Since the ban on the use of the organochlorine, organophosphates have been used increasingly to control pest infestation. Though neither as deadly nor as persistent as the organochlorines, organophosphates are potent inhibitors of acetylcholinesterase (Rao et al. 1984; Anthony 1986; Antwi 1987). A number of studies have shown that these chemicals cause, too, morphopathologic effects. Among these are vertebral malformations, parrot beak syndrome in fowl (Van Leewen et al. 1986), curved body, axis, blister formation and delayed melanogenesis in frog (Pawar et al. 1983), proliferation of type II pneumocytes, proliferation of interstitial cells and delayed septal and capillary development in lungs (Koizumi et al. 1988), atresia of follicles (Ansari et al. 1986), and demyelination and degeneration of axon (Hoffman et al. 1984), disruption of oogenesis in Pontius conchonus (Kumar and Pant 1988) and vacuolation of tubules and degeneration of glomeruli in Glorias batrachus (Mandal 1987). This study focuses on the histopathology of the telencephalon and diencephalon of Tilapia nilotica, exposed to commercial grade malathion. 


\section{MATERIALS AND METHODS}

\section{A. Chemical}

Malathion S-[1,2-di-(ethoxycarbonyl ethyl) dimethyl phosphorothiolothionate], commercial grade, $57 \mathrm{EC}$, used in the study for this concentration is utilized in agriculture, poultry and livestock spray. It is a deep brow $\sim$ to yellow liquid, slightly soluble in water (145-147 ppm), mixable with many organic solvents including alcohol, esters ketones, ethers, aromatic and alkylated hydrocarbons and vegetable oils. It has a limited solubility in certain paraffin hydrocarbons. It has a boiling point of $156-157^{\circ} \mathrm{C}$; melting point of $2.9^{\circ} \mathrm{C}$; density of $1.23 \mathrm{~g} / \mathrm{cc}$. It is hydrolyzed at $\mathrm{pH}>7.0$ or $<5.0$ but is stable in aqueous solution buffered to pH 5.26 (Merck Index 1983).

\section{B. Collection and Rearing of Fry}

Tilapia nilotica eggs, approximately 1000, were obtained from the Bureau of Fisheries and Aquatic Resources in Tanay, Rizal and allowed to hatch in finger bowls. The hatchlings were divided into control and experimental groups, each consisting of 300-350 larvae and reared in $1.0 \times 1.0 \times 1.5$ m concrete ponds in dechlorinated tap water until day 45, post-fertilization. Malathion, commercial grade, EC 57, diluted to sublethal doses of $0.3 \mathrm{ppm}$ and $3.0 \mathrm{ppm}$ served as pond water for the experimental group. Pond water was changed every week, taking care to maintain the dose concentration in the experimental pond.

\section{HISTOLOGICAL STUDIES}

\section{A. Paraffin Series}

Five fry from each group were harvested every three days until day 45 , fixed in Zenker's solution, dehydrated in alcohol series, sectioned serially at the brain region and stained in Delafied's Hematoxylin-Eosin for light microscopic examination. The sizes of nuclear centers in each brain region at a particular developmental stage were measured using an ocular micrometer (Fig. 1a and 1b). Statistical analyses of the data were done by the use of two-way ANOVA. 

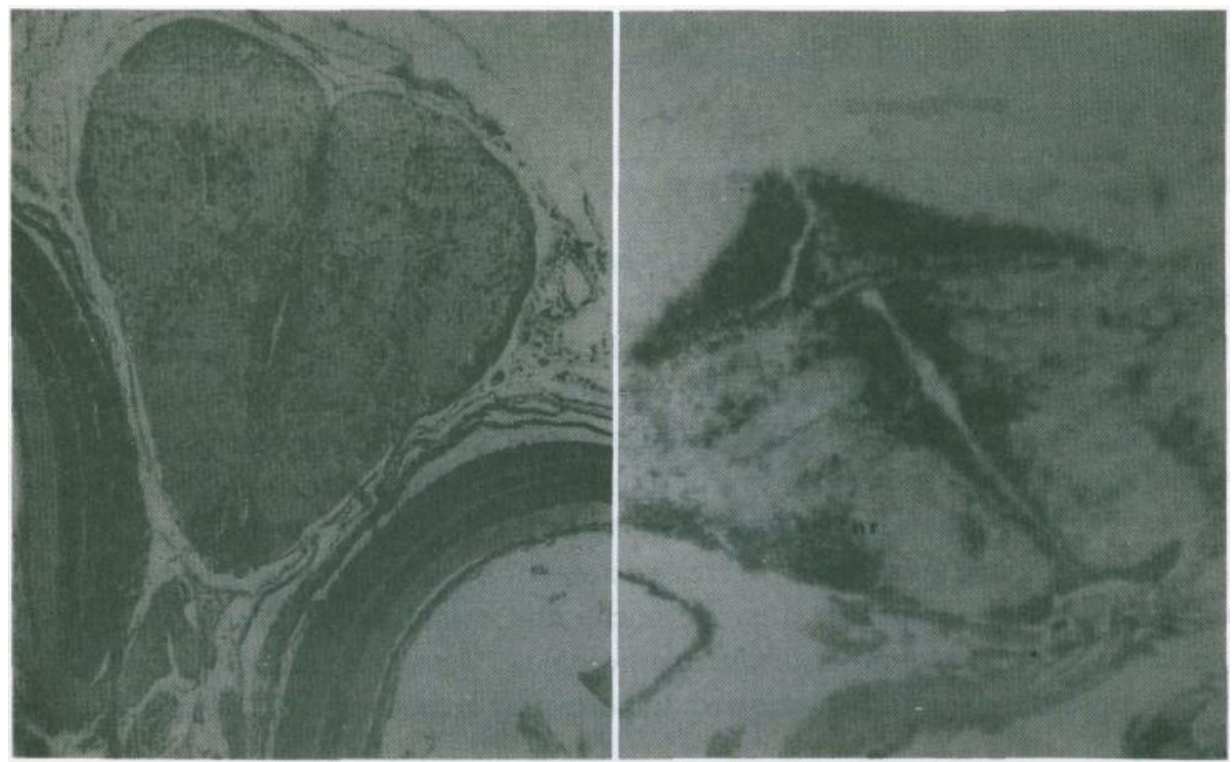

Figure 1a. Paraffin transverse section of themedial olfactory area of untreated, day-19, Tilapia nilotica. The olfacto-somatic area (os) consisted of small neurons. x 400

Figure 1b. Paraffin transverse section of the thalamus of untreated, day-45. Tilapia nilotica. The nucleus rotondus (nr) is a large nuclear center in the lateral region of the thalamus. $\mathrm{x} 400$

\section{B. Resin Sections}

Specimens were decapitated and heads were fixed overnight at $20^{\circ} \mathrm{C}$ in $2.5 \%$ glutaraldehyde in sodium phosphate buffer, $\mathrm{pH}$ 7.2. Brains were dissected and washed in Millonig's buffer for 45 minutes and fixed for one hour at $20^{\circ} \mathrm{C}$ in $1 \%$ osmium tetroxide. After a 45-minute buffer wash, they were dehydrated through an acetone series, embedded in Araldit (Luft's araldit formula) at $40-50^{\circ} \mathrm{C}$ for $24 \mathrm{~h}$ each and at $60^{\circ} \mathrm{C}$ for 3 days.

Sections for light microscopy were cut at 0.5 um using the LKB Ultramicrotome and stained with $1 \%$ toluidine blue. For electron microscopy, ultrathin sections, $100 \mathrm{um}$, were made with the same ultramicrotome, stained with $1 \%$ uranyl acetate, counterstained with lead citrate, and examined with JOEL, JEM 100U electron microscope. 


\section{RESULTS}

\section{Light Microscopy}

\section{A. Telencephalon}

The early histologic aberration which occurred among the free-swimming larvae, days 16-19, was the early differentiation of the olfacto-somatic area. Unlike in the control group, this nuclear center of embryos exposed to $0.3 \mathrm{ppm}$ malathion was composed of large polyploid neurons (Fig. 2). At this stage, too, the olfactory bulb and a number of nuclear centers had larger sizes than those of the control group which size differences persisted until day 35 (Table 1). Thereafter, the nuclei of treated embryos showed two types of changes: i) increased areas of olfactory bulb and olfacto-somatic areas and ii) decreased areas of nucleus olfactorius pars bulbaris, nucleus pars commissuralis, preoptic nuclei and somatic area (Table 1). Day 45 specimens showed a number of histopathologic effects. The medial olfactory area of $3.0 \mathrm{ppm}$-dosed embryos showed hypertrophy and increased vascularization (Fig. 3).

Table 1. Comparative sizes (um) of the nuclear centers in the telencephalon of Tilapia nilotica at specific developmental stage, post-fertilization

\begin{tabular}{|c|c|c|c|c|c|c|}
\hline \multirow{2}{*}{ NUCLEAR CENTER } & \multicolumn{3}{|c|}{ 11-15 Days } & \multicolumn{3}{|c|}{ 16-19 Days } \\
\hline & a & b & c & a & b & c \\
\hline $\begin{array}{l}\text { Nucleus olfactorius } \\
\text { pars bulbaris }\end{array}$ & $2507.5+123.8$ & $2809.77+349.42$ & $2858.67+525.65$ & $1804.30+282.26$ & $2363.86+108.03$ & $3239.61+256.01$ \\
\hline $\begin{array}{l}\text { Nucleus olfactorius } \\
\text { pars commissuralis }\end{array}$ & $5671.81+223.40$ & $5633.83+288.01$ & $5788.29+161.91$ & $4963.62+101.81$ & $4956.47+65.81$ & $5037.50+165.92$ \\
\hline Nucleus preopticus & $2665.43+268.46$ & $2626.89+72.56$ & $2625.96+87.89$ & $2797.17+155.68$ & $2737.23+104.85$ & $2675.13+220.17$ \\
\hline Olfacto-somatic area & $1821.53+67.33$ & $1840.18+98.46$ & $1823.64+81.07$ & $1899.04+23.56$ & $1902.68+52.19$ & $1893.45+27.24$ \\
\hline Somatic area & - & $*$ & * & * & $*$ & * \\
\hline Nucleus taenia & $*$ & $*$ & * & $110.37+10.73$ & $111.15+10.91$ & $111.15+10.92$ \\
\hline \multicolumn{7}{|c|}{ Values are MEAN - STANDARD DEVIATION } \\
\hline
\end{tabular}

a. Control fish; b. Embryos exposed to $0.3 \mathrm{ppm}$ malathion since day 10 , post-fertilization;

c. Embryos exposed to $3.0 \mathrm{ppm}$ malathion since day 10 , post-fertilization.

* Nuclear center is not observed. 
BIOTROPIA No. 5, 1991/1992

Table 1. Continued

\begin{tabular}{|c|c|c|c|c|c|c|}
\hline \multirow{2}{*}{ NUCLEAR CENTER } & \multicolumn{3}{|c|}{ 20-28 Days } & \multicolumn{3}{|c|}{ 29-35 Days } \\
\hline & a & b & c & a & $b$ & c \\
\hline $\begin{array}{l}\text { Nucleus olfactorius } \\
\text { pars bulbaris }\end{array}$ & $2925.97+4185.91$ & $4717.32+117.98$ & $2883.71+107.01$ & $3514.59+485.75$ & $5257.02+4855.75$ & $3490.44+99.81$ \\
\hline $\begin{array}{l}\text { Nucleus olfactorius } \\
\text { pars commissuralis }\end{array}$ & $1028.95+89.09$ & $1770: 17+223$ & $1888.03+65.77$ & $1242.15+31.34$ & $1442.13+33.61$ & $1480.70+53.89$ \\
\hline Nucleus preopticus & $257.17+18.83$ & $329.65+44.25$ & $337.39+52.87$ & $273.92+30.22$ & $309.95+43.24$ & $263.13+24.32$ \\
\hline Olfacto-somatic area & $207.22+38.62$ & $209.91+14.67$ & $189.49+6.48$ & $190.41+6.64$ & $169.99+15.17$ & $168.39+25.27$ \\
\hline Somatic area & $18780.90+581.25$ & $20364.30+735.00$ & $20560.60+1215.70$ & $20274.9+729.74$ & $12761.00+1239.20$ & $12005+1176.45$ \\
\hline Nucleus taenia & $622.60+56.57$ & $758.21+77.03$ & $918.69+57.78$ & $736.40+98.69$ & $1214.85+128.31$ & $1026.52+84.23$ \\
\hline
\end{tabular}

\begin{tabular}{lccc}
\hline NUCLEAR CENTER & \multicolumn{3}{c}{$36-45$ Days } \\
& a & b & \\
\hline Nucleus olfactorius & $3505.30+138.80$ & $2202.58+370.88$ & $3341.79+462.10$ \\
pars bulbaris & & & \\
Nucleus olfactorius & $1428.92+29.10$ & $1560.00+39.30$ & $1992.25+58.40$ \\
pars commisuralis & & & \\
Nucleus preopticus & $375.63+26.40$ & $333.29+38.40$ & $258.56+27.50$ \\
Olfacto-somatic area & $190.85+17.50$ & $121.59+11.10$ & $181.25+269.00$ \\
Somatic area & $20927.40+591.40$ & $19836.80+820.90$ & $19396.40+835.80$ \\
Nucleus taenia & $843.60+77.80$ & $618.87+40.60$ & $819.26+67.30$ \\
\hline
\end{tabular}

Table 2. Comparative sizes (um2) of selected nuclear centers in the diencephalon of Tilapia nilotica at specific developmental stage, post-fertilization

\begin{tabular}{|c|c|c|c|c|c|c|}
\hline \multirow{2}{*}{ NUCLEAR CENTER } & \multicolumn{3}{|c|}{ 11-15 Days } & \multicolumn{3}{|c|}{ 16.19 Days } \\
\hline & a & b & c & a & $b$ & c \\
\hline Habenula & $1287.92+86.94$ & $1286.54+25.19$ & $1294.40+31.42$ & $1816.89+53.95$ & $1688.10+52.50$ & $1681.36+49.47$ \\
\hline $\begin{array}{l}\text { Nucleus geniculatus } \\
\text { lateralis }\end{array}$ & $767.87+28.97$ & $599.30+44.00$ & $617.72+27.71$ & $923.06+50.10$ & $1368.89+49.18$ & $1354.81+49.90$ \\
\hline Nucleus rotondus & $154.39+12.79$ & $174.81+17.29$ & $158.06+13.23$ & $222.99+111.05$ & $219.78+17.37$ & $211.29+25.25$ \\
\hline Nucleus prerotondus & $135.81+5.55$ & $136.27+5.59$ & $136.73+8.32$ & $159.67+9.79$ & $156.69+10.79$ & $160.59+17.45$ \\
\hline Inferior lobe & $10899.50+662.61$ & $10943.90+1770$ & $9469.98+3440.3$ & $11787.30+5171.27$ & $10521.80+710.97$ & $10378.40+3579.77$ \\
\hline Hypophysis & $474.38+94.15$ & $456.30+50.55$ & $439.01+37.49$ & $557.42+25.88$ & $588.35+28.23$ & $564.04+\$ 2.18$ \\
\hline Values are MEAN - S & ARD DEYIATION & & & & & \\
\hline
\end{tabular}

a. Control group; b. Embryos are treated with $0.3 \mathrm{ppm}$ malathion since day 10 , post- Eertilization;

c. Enbryos are treated with $3.0 \mathrm{ppm}$ malathion since day 10 , post-iertilization. 
Histopathology of the telencephalon and diencephalon - Edna A. Amparado

Table 2. Continued

\begin{tabular}{lccccccc}
\hline \hline NUCLEAR CENTER & \multicolumn{5}{c}{$20-28$ Days } & \multicolumn{5}{c}{29.35 Days } \\
& \multicolumn{1}{c}{$\mathrm{a}$} & $\mathrm{b}$ & $\mathrm{c}$ & $\mathrm{a}$ & $\mathrm{b}$ & $\mathrm{c}$ \\
\hline Habenula & $2925.97+4185.91$ & $4717.32+117.98$ & $2883.71+107.01$ & $3514.59+485.75$ & $5257.02+4855.75$ & $3490.44+99.81$ \\
Nucleus geniculatus & $1028.95+89.09$ & $1770.17+223$ & $1888.03+65.77$ & $1242.15+31.34$ & $1442.13+33.61$ & $1480.70+53.89$ \\
lateralis & & & & & & & \\
Nucleus rotondus & $257.17+18.83$ & $329.65+44.25$ & $337.39+52.87$ & $273.92+30.22$ & $309.95+43.24$ & $263.13+24.32$ \\
Nucleus prerotondus & $207.22+38.62$ & $209.91+14.67$ & $189.49+6.48$ & $190.41+6.64$ & $169.99+15.17$ & $168.39+25.27$ \\
Inferior lobe & $18780.90+581.25$ & $20364.30+735.00$ & $20560.60+1215.70$ & $20274.00+729.74$ & $12761.00+1239.20$ & $12005+1176.45$ \\
Hypophysis & $622.60+56.57$ & $758.21+77.03$ & $918.69+57.78$ & $736.40+98.69$ & $1214.85+128.31$ & $1026.52+84.23$ \\
\hline
\end{tabular}

\begin{tabular}{lrrr}
\hline \hline NUCLEAR CENTER & \multicolumn{3}{c}{$36-45$ Days } \\
& \multicolumn{1}{c}{$\mathrm{a}$} & $\mathrm{b}$ & \multicolumn{1}{c}{$\mathrm{c}$} \\
\hline Habenula & $3505.30+138.80$ & $2202.58+370.88$ & $3341.79+462.10$ \\
Nucleus geniculatus & $1428.92+29.10$ & $1560.00+39.30$ & $1992.25+58.40$ \\
lateralis & & & \\
Nucleus rotondus & $375.63+26.40$ & $333.29+38.40$ & $258.56+27.50$ \\
Nucleus prerotondus & $190.85+17.50$ & $121.59+11.10$ & $181.25+269.00$ \\
Inferior lobe & $20927.40+591.40$ & $19836.80+820.90$ & $19396.40+835.80$ \\
Hypophysis & $843.60+77.80$ & $618.87+40.60$ & $819.26+62.30$ \\
\hline
\end{tabular}

\section{B. Diencephalon}

Larger nuclear centers than those of the control group were observed as early as day 16 and the disparity in sizes persisted until day 45, post-fertilization. Table 2 shows the sizes (um) of selected diencephalic nuclei at specified developmental stage. During the late free-swimming stage, day 16-19, the epithalamic centers were larger than those of the control while other nuclear centers were smaller. On days 21-28, nuclear masses were much larger than those of the control. On days 36-45, a number of nuclear centers exhibited regression in sizes with the notable exception of hypophysis and nucleus geniculatus lateralis which showed steady increase in sizes. In the dorsal thalamus, the region lateral to the nucleus ventrolateralis thalami showed hypertrophy (Fig. 4). 
Histopathology of the telencephalon and diencephalon - Edna A. Amparado

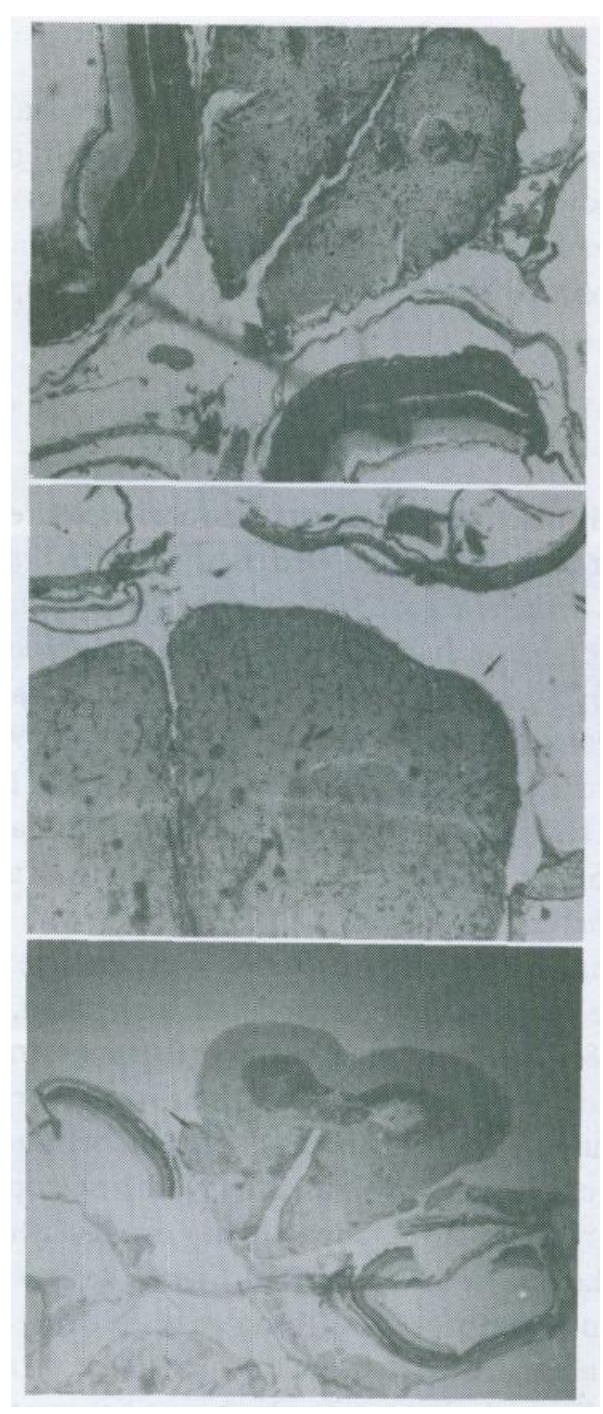

Figure 2. Paraffin transverse section of the medial olfactory area of day-19 Tilapia nilotica exposed to 0.3 ppm malathion since day 10, post fertilization. The olfacto-somatic area (os) consisted of large polyploid neurons. $\mathrm{x} 400$

Figure 3. Paraffin transverse section of the medial olfactory area of day-45 Tilapia nilotica exposed to 3.0 ppm malathion since day 10, post fertilization. The brain showed hypertrophy (arrow) and increased vascularization (arrowhead). x 400

Figure 4. Paraffin transverse section of the thalamus of day-45 Tilapia nilotica exposed to 3.0 ppm malathion since day 10, post fertilization. The lateral region showed hypertrophy (arrow). x400 


\section{BIOTROPIA No. 5, 1991/1992}

\section{Electron Microscopy}

Ultrastructure defects were observed in the telencephalic and diencephalic neurons of pesticide-exposed fishes. The electromicrograph of normal neurons of T. nilotica in day-45 is shown in Fig. 5. In both 0.3 and 3.0 ppm malathion exposed fish, the nucleus showed blebbing, ruffling and nucleolar disintegration (Fig. 6). Extensive vacuolations and lysosomal bodies were observed in the cytoplasm (Fig. 7 and 8).

\section{DISCUSSION}

The present study describes the impact of chronic exposure to commercial grade malathion on the neurons of Tilapia nilotica embryos. Membrane deformations are similar to the necrosis in the brain of Pacific herring larvae, Clupea harenguipallasi, exposed to crude oil (Cameron and Smith 1980), larvae hatched from eggs that have been incubated in varying concentrations of zinc (Somasundaram et al. 1984) and in Paraclithys lethosigma exposed to mercury (Trump et al. 1975) and mouse brain exposed to the neurotoxicant trimethyltin (Chang et al. 1982). Necrosis is attributed to the binding of the toxicant to the SH group in the neuronal membrane (Trump et al. 1978), failure of the neuronal plasma membrane ATPase system (Chang et al. 1982) and interaction of the lipophilic pesticide with the cell membrane (Triebskorn and Kunast 1990), and increase in acetylcholine release that induced increased membrane permeability to sodium, potassium, and calcium ions (Kabayashi et al. 1988). These authors contend that changes in fluid and electrolyte balance resulted in membrane damage. While these researchers categorized nuclear damage as effects caused by lethal concentrations, in this study, nuclear blebs are induced by sublethal concentrations. Interestingly, these cytopathologic conditions are observed only on older embryos, day 45 to day 60 specimens. Chronic exposure may have exhausted the defense mechanisms such as the depletion of energy resources needed to initiate protective processes (Recio et al. 1988).

Other histopathologic effects include hypertrophy of a number of nuclear centers and increased vascularization. Such aberrations were observed in the gill epithelium of teleosts exposed to acute doses of heavy metals such as zinc (Khangarat 1982), cadmium (Norgren et al. 1988), copper, silver and lead (Simula 1988). Similarly, thickening of the basement membrane of the digestive tract of the garden slug resulted from exposure to lethal dose of carbamate molluscide Chloethocarb (Triebskorn and Kunast 1990). The observations that hypertrophy and increased vascularization were visible in day 45 embryos may indicate that prolonged exposure to sublethal concentrations eventually produce histologic aberrations induced by lethal exposure. These pathomorphologic changes may be due to prolonged 
Histopathology of the telencephalon and diencephalon - Edna A. Amparado
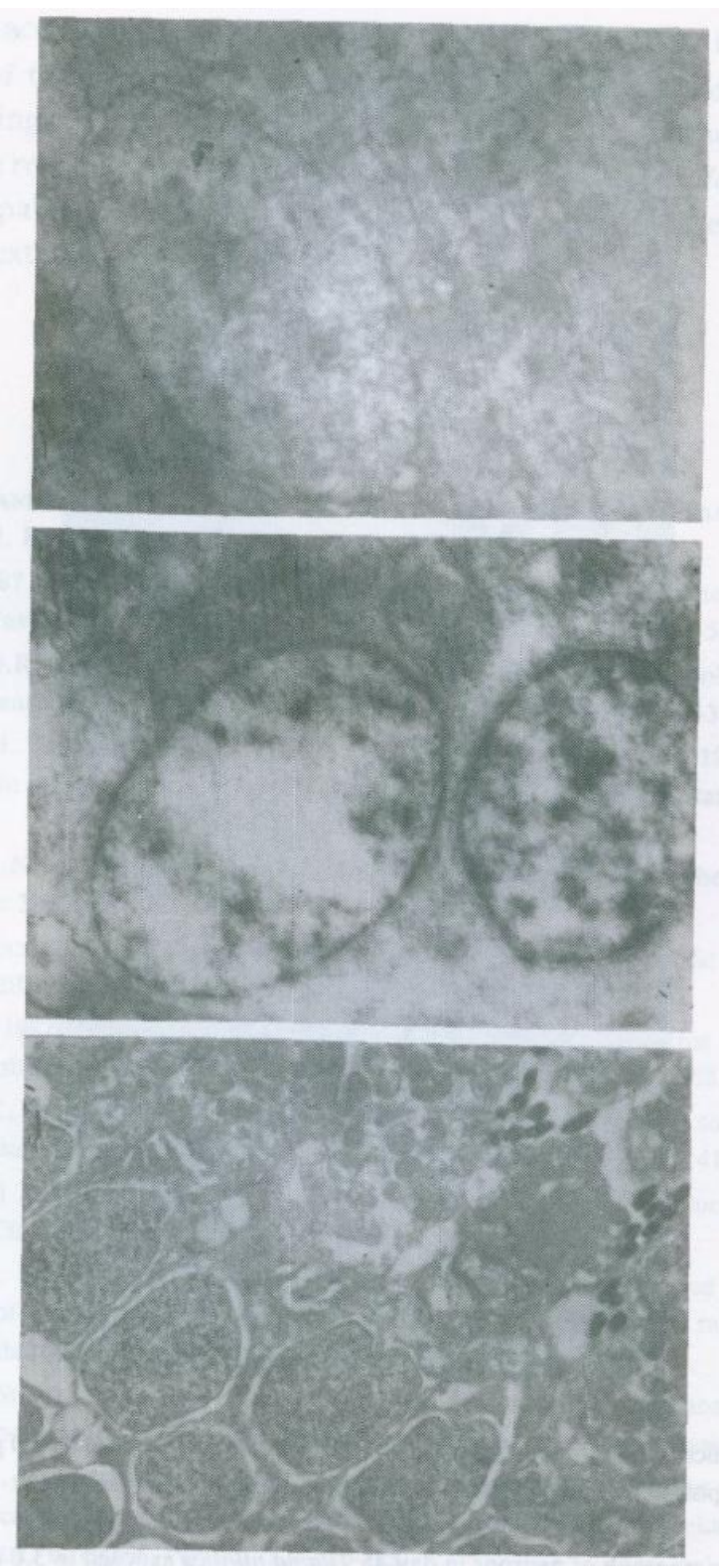

Figure 5. Electromicrograph of normal neurons in day-45 Tilapia nilotica. The nuclear membrane is intact and the cytoplasm does not exhibit vacuolization. x 6000 

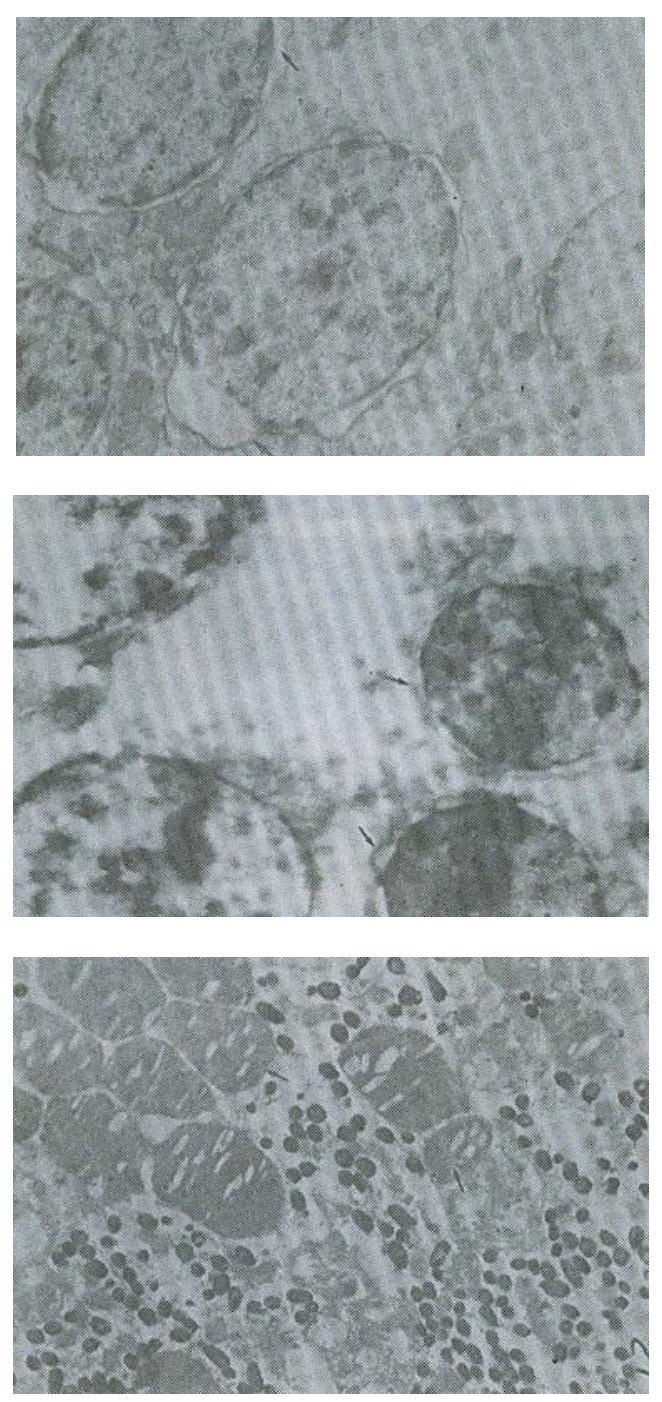

Figure 6. Electromicrograph of neurons in day-45 Tilapia nilotica exposed to $3.0 \mathrm{ppm}$ malathion since day 10, post fertilization. Neurons exhibited nuclear blebs (arrow), x 6000

Figure 7. Electromicrograph of neurons in day-45 Tilapia nilotica exposed to $3.0 \mathrm{ppm}$ malathion since day 10, post fertilization. Cytoplasmic vacuolations were extensive in both the telencephalon and diencephalon. x 6000

Figure 8. Electromicrograph of neurons in day-45 Tilapia nilotica exposed to $3.0 \mathrm{ppm}$ malathion since day 10, post fertilization. Lysosomal bodies were rampant in the cytoplasm, x 6000 
deprivation of acethylcholinesterase which is required for cellular interactions in the maintenance of the nervous system structure (Chase and Kankel 1988).

The findings that pesticides cause numerous neuronal pathology have repercussions on the reproductive functions and life span of Tilapia nilotica. That a very low dose is capable of producing various neuron aberrations, evaluation on the intensive and extensive use of pesticides is an urgent necessity.

\section{REFERENCES}

ANTHONY,J., E. BANISTER and P.C. OLOFF. 1986. Effects of sublethal levels of diazinon: histopathology of liver. Bull. Environ. Contain. Toxicol. 37: 501-507.

ANTWI, L.A.K. 1987. Fish head acetylcholinesterase after aerial application of tenephos in two rivers in Burkina Faso, West Africa. Bull. Environ. Contain. Toxicol. 37: 501-507.

CHASE, B.A. and D.R. KANKEL. 1988. On the role of normal acetylcholine metabolism in the formation and maintenance of the Drosophila nervous system. Dev. Biol. 125: 361-380.

CHANG,LW., T.M. TRIEMEYER, G.R. WENGER,P.E. MCMILLAN, K.R. REUHL. 1982. Neuropathology of trimethyltin intoxication. II. Electron microscopy study on the hippocampus. Env. Res. 29: $445-458$.

CHANG, L.W. 1983. Neuropathology of trimethyltin intoxication III. Changes in the brain stem neurons. Env. Res. 30: 399-411.

DELPIRE, E., C. DUCHENE, G. GOESSENS and R. GLLES. 1985. Effects of osmotic shocks on the ultrastructure of different tissues and cell types. Ex. Cell. Res. 160: 106-116.

KHANGAROT, B.S. 1982. Histopathological changes in the branchial apparatus of Pontius sophore (Hamilton) subjected to toxic doses of zinc. Arch. Hydrobiol. 93: 352-358.

KUMAR, S. and S.C. PANT. 1988. Comparative sublethal ovarian pathology of some pesticides in the teleost. Pontius conchonius Hamilton. Bull. Environ. Contain. Toxicol. 41: 227-231.

MANDAL,P.K. and A.K. KULSHRESTHA. 1980. Histopathological changes induced by the sublethal smithion in Glorias batrachus L. Indian J. Exp. Biol. 18: 547-552.

NORGREN, L.K., P. RUNN, C. HAUX and L. FORLIN. 1985. Cadmium induced changes in the gill morphology of zebrafish, Brachydamio nerio (Hamilton-Buchanan) and rainbow trout, Salmo gairdneri (Richardson). J. Fish Biol. 27: 81-95.

PANT, J.C. and T. SINGH. 1983. Inducement of metabolic dysfunction by carbamate and organophosphorous compounds in a fish, Pontius conchonius. Pestic. Biochem. Physiol. 20: 294-298.

RAO, D.M. and A.S. MURTHY. 1980. Toxicity, biotransfortmation and elimination of endosulfan to the Indian major carp, Catla catla with special reference to some biochemical changes induced by the pesticide. Pestic. Biochem. Physiol. 33: 220-229.

RECIO, A., A. MARJGOMEZ, E. ANGULOand J. MOYA. 1988. Zinc treatment of the digestive gland of the slug Arion ater L. 2. Sublethal effects at the histological level. Bull. Environ. Contain. Toxicol. 41: 865-871.

SUNILA, I. 1988. Acute histological responses of the gill of mussel, Mytilus edulis to exposure by environmental pollutants. J. Inverteb. Pathol. 52: 137-141. 
TRIEBSKORN, R. and C. KUNAST. 1990. Ultrastructural changes in the digestive system of Deroceras reticulatum (Mollusca: Gastropoda) induced by lethal and sublethal concentrations of the carbamate molluscicude Cloethocarb. Malacologia 32: 87-104.

VANLEEUWEN.C. J., T. HELDER and W. SEINEN. 1986. Aquatic lexicological aspects of dithiocarbamates and related compounds. IV. Teratogenicity and histopathology in rainbow trout (Salmo gairdnerf). Aq. Toxicol. 9: 247-259.

WESTER, P.W. and J.H. CANTON. 1986. Histopathological study of Oryzias latipes after long-term B-hexachlorocyclohexane exposure. Aq. Toxicol. 9: 21-45. 